\title{
CONCURRENT MANUFACTURING PROCESS SELECTION FOR NATURAL FIBRE THERMOPLASTIC COMPOSITES
}

\begin{abstract}
In this study, the manufacturing process for the natural fibre composite is selected with consideration of all elements of design composition in concurrent engineering practice. This includes materials, function, failure mode, and geometry, which interact simultaneously when the correct decisions have been made. All the elements have been determined in the previous study and the manufacturing process is the only element omitted, which needs to be determined. In this study, after preliminary selection, injection moulding, reaction injection moulding, resin transfer moulding, bulk moulding compound moulding and polymer casting are the potential manufacturing processes for the natural fibre composite automotive anti-roll bar with respect to the design composition. The obtained final selection results revealed that the injection moulding process was ranked top compared to other candidate processes; it satisfied most of the general manufacturing requirements by scoring $28.7 \%$ from the overall score. Next, sensitivity analysis was performed to confirm the stability of the judgement, and injection moulding maintained its position in three different cases. The results implied that all the elements in the design composition should interact for better quality and performance of the natural fibre composite products, and concurrent engineering practice is the most appropriate design strategy for the product design development.
\end{abstract}

Keywords: Concurrent engineering; manufacturing process selection; natural fibre composites; automotive anti-roll bar

\section{Introduction}

In concurrent engineering practice, all product design activities are integrated systematically in order to reduce lead time from conceptual design to manufacturing process by considering all the design issues at the early stage of the process (Sapuan \& Mansor, 2014). Concurrent engineering has been applied effectively by Toyota, one of the biggest automakers worldwide. In their application, they found out that more time is spent at the early stage of the design process where several decisions have to be made in terms of the materials, conceptual design requirement, configuration and manufacturability. However, they could move faster to another stage of activities in the design process until the production than the traditional design method (Sobek II, Ward, \& Liker, Jeffrey, 1999). In the other study, Vinodh et al. (2010) had incorporated conceptual design selection in manufacturing organisation using Fuzzy Analytic Network Process (FANP) to improve the agility of product process development. In the production industry, time is closely related to cost, where more time spent on the total production process results in a higher cost. Therefore, concurrent engineering would be the best practice for automakers in product design development. Moreover, to reduce the cost of production, the automotive industry has utilised the great performance demonstrated by bio-materials such as natural fibre composites in their automotive component designs. The production of automotive 
components that are based on alternative materials such as natural fibre composites requires a higher systematic approach to avoid risks in terms of cost, time and energy. Most manufacturing technology is designed for common material characteristics such as metal and plastic. However, manufacturing technology for composite materials is designed to tailor the desired properties of the final materials by mixing the fibre and matrix. It is highly dependent on the fibres' arrangement, geometry, volume fraction, and pre-treatment method (Ho et al., 2012). Choosing the right materials for the right manufacturing process is very important because they are closely related to each other. Therefore selection of the manufacturing process in consideration with materials constraints at an early stage of product design development would offer more advantages to overall production of natural fibre composite based product.

\section{Literature Review}

Selecting a manufacturing process requires a connection between the other design elements. As studied by Lovatt and Shercliff (1998), material, shape and process are the important elements in engineering design. In order to find the best design solution, activities related to determining material characteristics, geometric configuration and manufacturing process should not be performed individually, as these elements should work together. Ashby (2004) also agrees with this principle, and adds one more element, which is function, in his proposed design technique. Function is added as one of the elements in the engineering design technique because, in the final process, the correct material's characteristics with the suitable geometric configuration and manufacturing process would produce a better design solution with respect to the function.

As a general rule of thumb, when selecting materials in product design, activities relating to the function and minimum cost are carried out after the manufacturing process has been selected (Mayyas, Omar, \& Hayajneh, 2016). However, this general rule of thumb is relevant if the design engineers prefer traditional materials rather than alternative materials. If the material selection is performed at the final stage of product design development, the decision could be restricted to readily available materials and there would be no room for design improvement (Evbuomwan, Sivaloganathan, \& Jebb, 1995). Therefore, in modern design process practice, material and manufacturing processes could be performed simultaneously, as suggested in concurrent engineering.

Similar to material selection, geometry specification is also one of the activities that need to be considered in parallel with the manufacturing process selections. The geometry of the final product needs to be identified earlier in order to have only a narrow range of candidates for the appropriate manufacturing process. Some of the manufacturing processes are designed to produce a final product with certain geometric restrictions (Woude \& Lawton, 2010). These restrictions could help engineers to eliminate any manufacturing processes that are not adequate to produce the desired product design, and this will save more time in the decision-making process. Yurdakul et al. (2014) had introduced a decision support system that particularly selecting the net-shape primary shaping process to manufacture. They considered the capability of some primary processes in terms of the weight, shape, section thickness and surface finish. In the design of composite products, geometry specification requires details of material properties and processability evaluation with respect to the particular function. These basic elements should be defined simultaneously in concurrent engineering environment to save time, cost 
and energy in design project. As manufacturing process selection is one of the elements, this would help engineers to perform preliminary analysis on the manufacturing process selection and the irrelevant manufacturing process will be eliminated in less time.

\section{Objectives}

In this study, a manufacturing process selection approach for natural fibre composites is proposed concurrently in product design development and a natural fibre composite-based automotive anti-roll bar (ARB) is taken as a case study. The proposed approach includes preliminary analysis that would allow engineers to be prepared for any manufacturing issues that might arise after the production. The manufacturing process selection is performed with regards with material, function, failure mode, and geometry. A multicriteria decision-making tool, AHP, is used to select the most appropriate manufacturing process for the natural fibre composite automotive ARB.

\section{Methodology}

As discussed earlier, determination of manufacturing process of natural fibre compositebased products is related to the selection of materials, function, failure modes and geometry. In a case study on design of automotive ARB, group of material for this automotive component is determined earlier in authors' (Mastura, Sapuan, Mansor, \& Nuraini, 2016) previous study and it will be the starting point to get through selection process of manufacturing process. The proposed approach for selecting the most appropriate manufacturing process for the natural fibre composite automotive ARB is presented in Fig. 1.

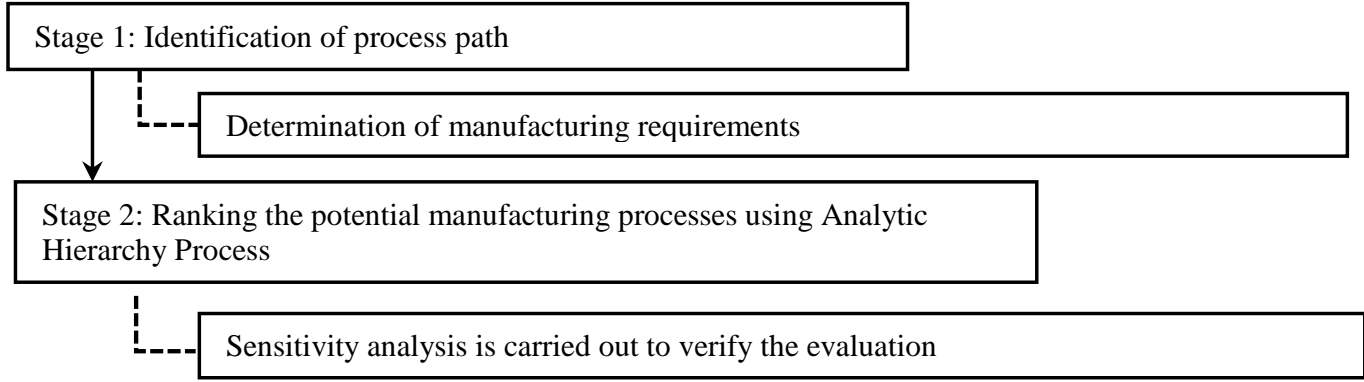

Fig. 1 Flow chart of manufacturing process selection for natural fibre composite product

\section{Selecting the manufacturing process using the Analytic Hierarchy Process}

Initially, the hierarchical framework in making a decision is constructed as presented in Fig. 2. Each of the criteria, sub-criteria and alternatives are evaluated on a pairwise comparison basis with respect to their level of superiority, as per the example in Fig. 3. The evaluations are based on the manufacturing process properties and each criterion's importance scale with respect to the main goal. The global weights attained by the criteria in level 2 are shown in Fig. 2. Obviously, the manufacturing process of the natural fibre composite automotive ARB has to offer a great process performance due to the high score 
ISAHP Article: A Style Guide for Paper Proposals To Be Submitted to the International Symposium on the Analytic Hierarchy Process 2018, Hong Kong, HK.

(50.8\%) gained for the global weight. Process performance is an important factor in the selection of an appropriate manufacturing process, as it will influence the overall product in terms of the price, quality and market value. The higher value for the production rate and production volume implies a lower price for the product in the market, and a shorter time in production will shorten the time to market and make the competitive market ( $\mathrm{Yu}$, 1992).

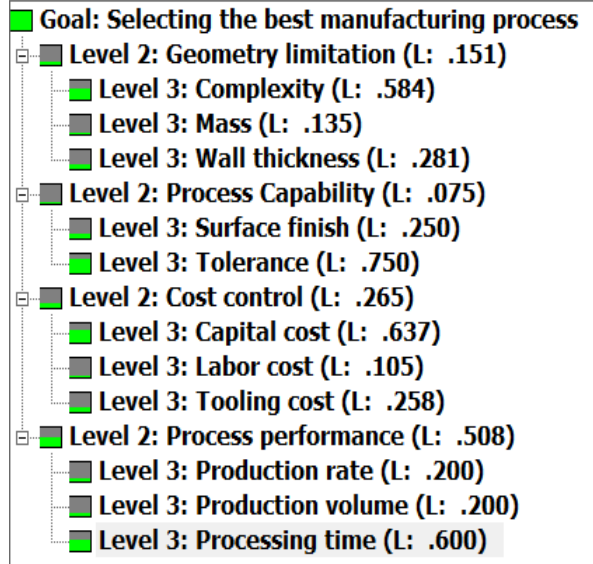

Fig. 2 Hierarchical framework for selecting the best manufacturing process for the automotive anti-roll bar with their weightage

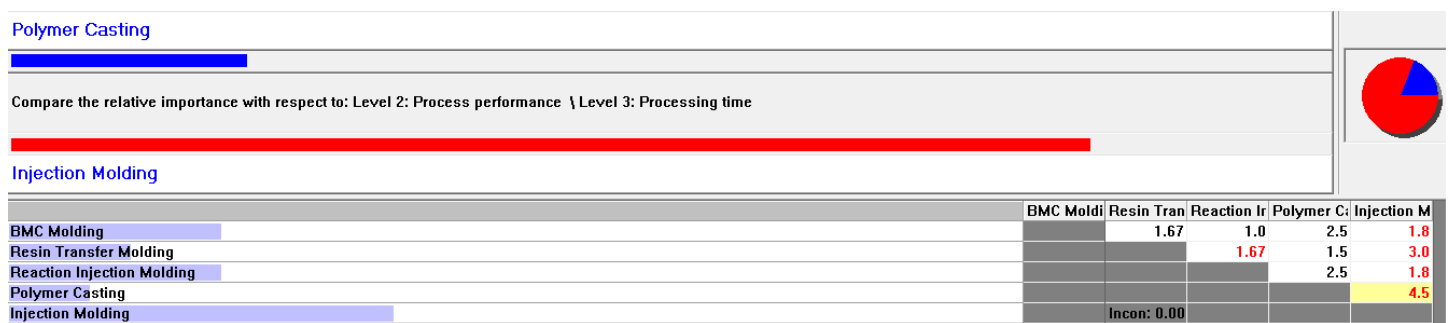

Fig. 3 Comparison on a pairwise basis of the manufacturing process with respect to processing time

Next, the result for the manufacturing process ranking is gained from the calculated priority vector obtained from the alternatives' scores, as in Fig. 4. The result shows that injection moulding obtained $28.7 \%$ of the overall score, followed by polymer casting (24.7\%), BMC moulding $(16.9 \%)$, reaction injection moulding $(15.3 \%)$ and resin transfer moulding (14.4\%). In addition, the overall judgement is considered consistent and acceptable since the overall consistency ratio from the Expert Choice is 0.05 , which is less than 0.1, as suggested by Raharjo et al. (2006). Hence, injection moulding is the most suitable manufacturing process for the natural fibre composite automotive ARB design with regard to the manufacturing requirements. 


\section{Goal: Selecting the best manufacturing process}

Resin transfer moulding Reaction injection moulding BMC moulding Polymer casting Injection moulding
0.144

0.153

0.169

Fig. 4 Ranking of the manufacturing process

Injection moulding is a common manufacturing process that has been applied for the production of various types of composite-based materials. Panthapulakka et al. (2004) conducted a study on the manufacturing process of automotive interior components made from natural fibre/glass reinforced thermoplastic hybrid composite materials. In their study, the thermal and mechanical properties of the natural fibre hybrid composite produced from injection moulding were greater than those of the other composites and could be used as substitute materials for plastic. Moreover, fibres like flax, jute, and sisal have specifically undergone an injection moulding process for the production of natural fibre polypropylene composites (Malkapuram, Kumar, \& Yuvraj Singh Negi, 2008).

\subsection{Sensitivity analysis}

The impact of changes on the global weights of the criteria was observed. The observation was focused on the ranking of the best manufacturing process. Each global weight was increased by $20 \%$, as presented in Fig. 5. As in the Fig. 5, injection moulding maintained its position at the top of the rank for all three different cases. However, when the global weight of the cost control was increased, injection moulding dropped to second rank, as the polymer casting was now first. Thus, it could still be claimed that the judgement on the best manufacturing process for the natural fibre composite automotive ARB is stable and not dominated by one preference.

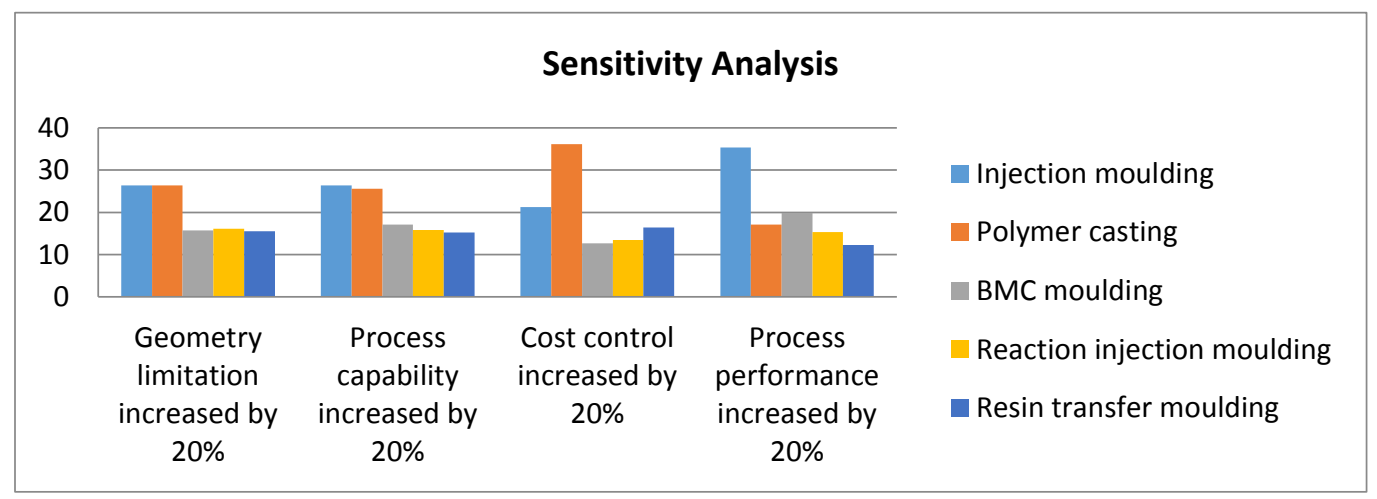

Fig. 5 Graph of sensitivity analysis on judgement towards selecting the best manufacturing process

\section{Limitations}

Material selection and manufacturing process selection should be performed simultaneously as a new framework should be created. In this study, there is lack of 
ISAHP Article: A Style Guide for Paper Proposals To Be Submitted to the International Symposium on the Analytic Hierarchy Process 2018, Hong Kong, HK.

information regarding on the selection of natural fibres. Moreover, design geometry or shape of the product also should be selected together in parallel of making decision for the suitable manufacturing process. Therefore, additional information in terms of materials and geometry should be put in this approach to satisfy all the design requirements.

\section{Conclusions}

In conclusion, the process of selecting a manufacturing process for a natural fibre composite-based product requires interaction between each of the design elements. Interaction in the design composition would imply the better quality and high performance of a design composite-based product where all the critical issues regarding the materials, function, failure mode, geometry and process are considered simultaneously. This practice would save time, cost and energy, where all the engineers from different departments are required for active participation in the design project. This could also give more opportunity for natural fibre composite materials to be applied in more applications and eliminate the negative perception of natural fibre composite-based products. Furthermore, concurrent engineering is convincingly the most appropriate engineering design practice for natural fibre composite-based products. Through this study, the decision on suitable manufacturing process for natural fibre composite automotive ARB is made as injection moulding is selected as the primary manufacturing process for the ARB. Further study need to be conducted as the selected primary manufacturing process has its limitation. Incorporation with another manufacturing process is required to ensure the desired quality and performance of the natural fibre composite ARB could be achieved and the design could be fabricated.

\section{Key References}

Ashby, M. F. (2004). Materials Selection in Mechanical Design (3rd ed.). Oxford: Elsevier Butterworth-Heinemann.

Mastura, M. T., Sapuan, S. M., Mansor, M. R., \& Nuraini, A. A. (2017). Environmentally conscious hybrid bio-composite material selection for automotive anti-roll bar. The International Journal of Advanced Manufacturing Technology, 89(5), 2203-2219.

Raharjo, H., \& Endah, D. (2006). Evaluating Relationship of Consistency Ratio and Number of Alternatives on Rank Reversal in the AHP. Quality Engineering, 18, 3946.

Sapuan, S. M., \& Mansor, M. R. (2014). Concurrent engineering approach in the development of composite products: A review. Materials \& Design, 58, 161-167.

Yurdakul, M., Arslan, E., İ, Y. T., \& Türkba, O. S. (2014). A decision support system for selection of net-shape primary manufacturing processes. International Journal of Production Research, 52(5), 1528-1541. 